\title{
COMMENTARY
}

\section{Balanced study groups in a randomized trial - authors' response}

\author{
Jan Benes*, Ivan Chytra, Richard Pradl and Eduard Kasal \\ See related research by Benes et al., http://ccforum.com/content/14/3/R118
}

Thank you for giving us the chance to reply to the comment raised by Dr Munis [1]. As we wrote in the Materials and methods section of our article [2], we used a sealed envelope, simple randomization procedure in a 1:1 proportion of intervention to control. No stratification was performed, although there are some factors affecting the study group homogeneity.

The strict inclusion and exclusion criteria resulted in a narrow spectrum of patients in the study: 'healthier' patients were not entered, and 'sicker' patients usually underwent a less invasive procedure. Also, disease prevalence is not independent in such a homogenous group; for instance, patients undergoing abdominal aortic surgery (comprising 66\% of included patients) were mostly men aged over 60 years and smokers. The association with peripheral artery disease is given by the procedure itself; hypertension, ischemic heart disease and pulmonary pathologies are common. When the procedure distribution is balanced, the same could be expected with associated variables. This can affect similar balancing observed in other optimization studies [3-5].

Also, we have to admit that the list of demographic data (Table 2 in [2]) was not comprehensive. Some screened, but not entirely important, conditions were omitted for reasons of conciseness. The absence of these rarer states could contribute to the image of balanced study groups. These conditions are now listed in Table 1 here.

In conclusion, though our study was not intentionally stratified, the population homogeneity and dependence on disease prevalence could create some sort of 'prestratification. With the inclusion of the rare conditions, however, the groups are not that balanced. We hope our explanation helps to elucidate and answer the problem raised by Dr Munis.

*Correspondence: benesj@fnplzen.cz

Department of Anesthesiology and Intensive Care, Charles University hospital, alej Svobody 80, Plzen, 304 60, Czech Republic
Table 1. Chronic disease conditions

\begin{tabular}{lccc}
\hline Condition & $\begin{array}{c}\text { Vigileo group } \\
(\mathbf{N}=60)\end{array}$ & $\begin{array}{c}\text { Control group } \\
(\mathbf{N}=60)\end{array}$ & P-value \\
\hline Pancreatitis in anamnesis & $2(3 \%)$ & $0(0 \%)$ & 0.4758 \\
Obesity & $5(8 \%)$ & $10(17 \%)$ & 0.2695 \\
$\begin{array}{l}\text { Pulmonary embolism } \\
\text { in anamnesis }\end{array}$ & $5(8 \%)$ & $2(3 \%)$ & 0.4360 \\
$\begin{array}{l}\text { Chronic liver disease } \\
\text { (usually mild to severe) }\end{array}$ & $5(8 \%)$ & $2(3 \%)$ & 0.4360 \\
\hline
\end{tabular}

\section{Competing interests}

After publishing the original article, JB received speaker's fees from Edward Lifesciences Inc. The other authors declare that they have no other competing interests.

\section{Acknowledgements}

The study was supported by a research grant of Czech Ministry of Education, MSM0021620819.

Published: 8 December 2011

\section{References}

1. Request for clarification of randomization method [http://ccforum.com/content/14/3/R118/comments]

2. Benes J, Chytra I, Altmann P, Hluchy M, Kasal E, Svitak R, Pradl R, Stepan M: Intraoperative fluid optimization using stroke volume variation in high risk surgical patients: results of prospective randomized study. Crit Care 2010, 14:R118.

3. Van der Linden PJ, Dierick A, Wilmin S, Bellens B, De Hert SG: A randomized controlled trial comparing an intraoperative goal-directed strategy with routine clinical practice in patients undergoing peripheral arterial surgery. Eur J Anaesthesiol 2010, 27:788-793.

4. Boyd O, Grounds RM, Bennett ED: A randomized clinical trial of the effect of deliberate perioperative increase of oxygen delivery on mortality in highrisk surgical patients. JAMA 1993, 270:2699-2707.

5. Mayer J, Boldt J, Mengistu A, Rohm K, Suttner S: Goal-directed intraoperative therapy based on autocalibrated arterial pressure waveform analysis reduces hospital stay in high-risk surgical patients: a randomized, controlled trial. Crit Care 2010, 14:R18.

doi:10.1186/cc10549

Cite this article as: Benes J, et al:: Balanced study groups in a randomized trial - authors' response. Critical Care 2011, 15:460. 